\title{
A EDUCAÇÃO FÍSICA DO ENSINO MÉDIO INTEGRADO: UMA REVISÃO DAS PUBLICAÇÕES CIENTÍFICAS NO BRASIL
}

\section{Integrated High School Physical Education: A Review of Scientific Publications in Brazil}

\author{
Michele da Silva Valadão Fernandes ${ }^{1}$ \\ Regina Márcia Ferreira Silva ${ }^{2}$ \\ Marco Antônio de Carvalho ${ }^{3}$ \\ Matias $\mathrm{Noll}^{4}$
}

\begin{abstract}
Resumo: Com o objetivo de avaliar as principais temáticas relacionadas às pesquisas que envolvem a Educação Física do ensino médio integrado no Brasil, este estudo foi feito a partir de uma revisão bibliográfica das publicações científicas nos programas de Pós-Graduação stricto sensu e de artigos científicos. O levantamento de teses e de dissertações utilizou como fonte a Biblioteca Digital Brasileira de Teses e Dissertações (BDTD). A busca de artigos científicos foi feita a partir da base de dados Scielo. Os estudos selecionados compreendem as publicações entre os anos de 2012 a 2019 e apresentam temáticas que se referem ao histórico da Educação Profissional dos Institutos Federais, ao histórico da Educação Física e sua relação com a Educação Profissional e Tecnológica, à análise da Educação Física na dinâmica curricular e às propostas de práticas pedagógicas para o ensino médio integrado. Constatamos que a baixa quantidade de produção científica pode levar ao entendimento da necessidade de maior discussão e pesquisa em relação à temática. Portanto, sugerimos que as pesquisas futuras apresentem propostas didático-pedagógicas que contribuam com a prática docente na Educação Física do ensino médio integrado.
\end{abstract}

Palavras-chave: Educação física. Ensino médio integrado. Estado da arte. Educação integrada. Educação profissional.

Abstract: A bibliographical review of scientific publications of stricto sensu graduate programs was done in order to evaluate the main themes related to research involving the discipline of Physical Education in integrated high school in Brazil. The source for the survey of theses and dissertations was the Brazilian Digital Library of Theses and Dissertations

\footnotetext{
${ }^{1}$ Mestranda em Educação Profissional e Tecnológica pelo Instituto Federal de Educação, Ciência e Tecnologia Goiano. Licenciada em Educação Física pela Universidade Estadual de Goiás. https://orcid.org/0000-0002-16139280. E-mail: michele.valadao@estudante.ifgoiano.edu.br

${ }^{2}$ Mestranda em Educação Profissional e Tecnológica pelo Instituto Federal de Educação, Ciência e Tecnologia Goiano. Bacharel em Sistemas de Informação. https://orcid.org/0000-0002-9829-0020. E-mail: regina.silva@ifg.edu.br

3 Doutor em Educação pela Pontifícia Universidade Católica de Goiás. Docente do Programa de Pós-Graduação em nível de Mestrado Profissional em Educação Profissional Tecnológica (ProfEPT/IF Goiano) https://orcid.org/0000-0002-5127-5886. E-mail: marco.carvalho@ifgoiano.edu.br

${ }^{4}$ Doutor em Ciências da Saúde pela Universidade Federal de Goiás. Docente do Programa de Pós-Graduação em nível de Mestrado Profissional em Educação Profissional Tecnológica (ProfEPT/IF Goiano). https://orcid.org/0000-0002-1482-0718. E-mail: matias.noll@ifgoiano.edu.br
} 
(BDTD). The search for scientific articles was made from the Scielo database. The selected studies include publications from 2012 to 2019 and present themes that refer to the history of Professional Education of Federal Institutes, the history of Physical Education and its relationship with Professional and Technological Education, to the analysis of Physical Education in curriculum dynamics and proposals for pedagogical practices for integrated high school. We found that the low amount of scientific production can lead to an understanding of the need for further discussion and research in relation to the topic. Therefore, we suggest that future research presents didactic-pedagogical proposals that contribute to the teaching practice in Physical Education of integrated high school.

Keywords: Physical Education. Integrated high school. State of art. Integrated education. Professional education.

\section{Introdução}

A Educação Física (EF) é o componente curricular que tem como objeto de conhecimento as distintas manifestações da cultura corporal de movimento, sendo a dança, a mímica, o esporte, as práticas circenses e os jogos parte dessa cultura (ALMEIDA; MARTINELI, 2018; BOSCATTO; DARIDO, 2017). Sua inserção na escola teve objetivos diversos, incluindo a promoção da saúde numa perspectiva médico-ortopédica e higienista ou associada às abordagens de cunho ginástico desportivo (VAGO, 2004). Todas elas baseadas em discursos hegemônicos e aos paradigmas socioeconômicos, políticos e culturais da sociedade moderna.

As práticas corporais e a apropriação da ginástica e do esporte pela escola, após o século XVIII, acabaram por reforçar concepções racionalistas e instrumentais de ensino (ALMEIDA; MARTINELI, 2018). Através dessas concepções, buscava-se a educação e disciplina do corpo para atender aos interesses capitalistas que se forjaram nas práticas pedagógicas da EF escolar. Estudos como o de Soares et al. (1992), de Kunz (1994), de Daolio (1994) e Bracht (1992, 1997), voltados para as concepções teóricas da EF escolar, intensificam-se a partir da década de 90 se opondo à lógica instrumental e racionalista, teorizando abordagens críticas na área. (BOSCATTO; DARIDO, 2017).

Fundamentadas na matriz histórico-cultural, as teorias críticas questionam o caráter alienante da EF na escola, buscando a superação das desigualdades sociais e enfatizam os níveis histórico, social e político que configuram as práticas corporais (SOARES et al., 1992; KUNZ, 1994; DAOLIO, 1994; BRACHT, 1992; 1997). Elas também possibilitam um diálogo extremamente pertinente ao tratarmos da EF na dinâmica da Educação Profissional e Tecnológica (EPT), mais especificamente, no contexto do ensino médio integrado. Contudo, não podemos nos limitar a elas, uma vez que não são absolutas e há de se considerar a $\mathrm{EF}$ a partir de seu pluralismo teórico. Almeida, Bracht e Vaz (2012) nos alertam sobre o cuidado em se evitar os reducionismos, entendendo que o mais importante é o avanço do debate epistemológico da área. Importa, a título deste breve estudo, fazer convergir às concepções teóricas da EF os pilares de uma educação integrada.

A educação integrada, na perspectiva gramsciana, deve contemplar dois pilares fundamentais: a educação unitária e politécnica (CIAVATTA, 2005). Segundo Ciavatta (2005; 2016) e Ramos (2008), o acesso à ciência, à cultura e ao trabalho por meio de uma educação básica e profissional parte da indissociabilidade entre formação profissional e formação geral. A formação omnilateral dos sujeitos também deve nortear o projeto de uma educação integrada, na medida em que considera todas as dimensões da vida dos alunos e 


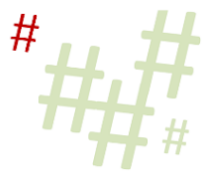

proporciona a integração dos distintos conhecimentos como totalidade curricular (FRIGOTTO, 2008; RAMOS, 2008).

O currículo integrado tem sido objeto de estudo em crescentes pesquisas em educação no Brasil (CIAVATTA, 2005; 2016; MOURA, 2007), principalmente no que se refere à Educação Profissional de nível médio, evidenciando profundas demandas do ponto de vista político, econômico, social e ideológico. Sua configuração pode ser observada no contexto do ensino médio integrado, presente nos projetos político-pedagógicos dos Institutos Federais de Educação, Ciência e Tecnologia (BRASIL, 1997; 2008). Esses projetos devem ser construídos em virtude da totalidade social, à qual Ciavatta (2016, p. 45) se refere enquanto projeto político educacional indispensável, "parte da formação humana, da educação omnilateral e do trabalho como princípio educativo".

Há inúmeras dificuldades intrínsecas à realidade docente nessa construção, uma vez que a formação docente e a própria organização dos sistemas de ensino estiveram organizadas para atender interesses imediatos do sistema capitalista, além de consolidar a fragmentação das ciências e seus respectivos campos de conhecimento (MOURA, 2007). Ainda que uma concepção do ensino médio integrado esteja bem desenhada, a prática se revela em constantes entraves e dificuldades de materialização (HENRIQUE; NASCIMENTO, 2015). Ressalta-se, nesse contexto, o dualismo histórico entre formação acadêmica e formação profissional, entre cultura geral e cultura técnica que esteve presente na etapa final da educação básica nacional (MOURA, 2007).

Podemos destacar que a superação do dualismo histórico na Educação Profissional é tão necessária quanto a superação das práticas pedagógicas na EF que reforçam a dicotomia entre a teoria e a prática, entre atividade intelectual e atividade corporal. Apesar de ser um componente curricular dos cursos técnicos integrados ao ensino médio, a gênese da EF na escola esteve alicerçada numa perspectiva de fragmentação do corpo e de total distanciamento das demais componentes do currículo escolar (FENSTERSEIFER, 2015). Esse distanciamento é ainda mais evidente se considerarmos a Educação Profissional (SILVA; FRAGA, 2014).

Portanto, faz-se extremamente necessária a ampliação do debate a respeito da EF do ensino médio integrado. As contribuições, relevância e a justificativa desse componente curricular estão relacionadas à efetivação de práticas didático-pedagógicas comprometidas com a formação crítica e integral dos estudantes. Sendo assim, é pertinente propor, neste artigo, o que tem sido denominado por alguns autores de estado da arte ou estado do conhecimento (FERREIRA, 2002; PALANCH; FREITAS, 2015). A referida revisão bibliográfica foi construída com o objetivo de avaliar as principais temáticas relacionadas às pesquisas que envolvem a $\mathrm{EF}$ do ensino médio integrado, descrevendo as características levantadas por estes estudos com relação à integração curricular, às abordagens teóricas e às propostas didático-pedagógicas.

\section{Metodologia}

As pesquisas conhecidas como "estado da arte" ou "estado do conhecimento" possuem cunho bibliográfico e exercem um papel primordial na produção do conhecimento científico. Ferreira (2002, p. 257) afirma que elas apresentam "[...] o desafio de mapear e de discutir uma certa produção acadêmica em diferentes campos do conhecimento, tentando responder que aspectos e dimensões vêm sendo destacados e privilegiados [...]". Ponto de partida crucial para qualquer pesquisador, que passa a conhecer as produções prévias e lacunas existentes em seu campo de pesquisa ou que envolvem seu objeto de estudo (PALANCH; FREITAS, 2015). 
Em relação à bibliografia, buscamos produções dos programas de Pós-Graduação stricto sensu e artigos científicos que tivessem relação com a EF escolar do ensino médio integrado. Para tanto, foram realizadas consultas na Biblioteca Digital Brasileira de Teses e Dissertações (BDTD) e na base de dados Scielo, utilizando os seguintes descritores: (i) "educação física", (ii) "ensino médio integrado", (iii) "educação profissional" e (iv) "ensino profissional". Dois revisores participaram da etapa de busca, seleção e extração de dados das publicações.

O período de consulta aos bancos de teses e dissertações aconteceu entre os dias 15 de setembro a 5 de dezembro de 2019. Os critérios de inclusão foram: a) Estudos com enfoque no ensino médio integrado (EMI); b) Estudos com enfoque na Educação Profissional Técnica de Nível Médio Integrado c) Estudos que tivessem como objeto de estudo a EF escolar. Os critérios de exclusão foram: a) Produções com enfoque exclusivamente no ensino médio propedêutico b) Produções envolvendo ambientes não formais de ensino.

\section{As produções acadêmicas identificadas}

Através do levantamento das publicações científicas por meio da BDTD e do Scielo, utilizando os critérios de busca e descritores já mencionados, obtivemos como resultado 15 trabalhos. Após a exclusão de um documento duplicado, da leitura dos títulos e resumos, foram selecionados 12 trabalhos, incluindo 8 dissertações de mestrado, 3 teses de doutorado e 1 artigo científico para a leitura na íntegra. O trabalho mais antigo data do ano de 2012 e o mais recente de 2019. Por meio de um inventário dessas produções, buscamos descrever os enfoques e perspectivas, analisando as contribuições e desdobramentos de cada estudo no campo da EPT de Nível Médio.

Elaboramos o Quadro 1, apresentado a seguir, para discriminar a instituição de ensino à qual a pesquisa está vinculada, o tipo de publicação científica (dissertação, tese ou artigo), ano de publicação, autor e título do trabalho.

Quadro 1 - Publicações científicas sobre Educação Física e ensino médio integrado.

\begin{tabular}{|c|c|c|c|l|}
\hline Instituição & Tipo & Ano & Autor (a) & \multicolumn{1}{c|}{ Título } \\
\hline UNICAMP & Dissertação & 2012 & $\begin{array}{c}\text { Marcilio Lourenço da } \\
\text { Cunha }\end{array}$ & $\begin{array}{l}\text { O percurso da Educação Física no } \\
\text { Instituto Federal de Santa Catarina - } \\
\text { Campus São José }\end{array}$ \\
\hline UFBA & Dissertação & 2013 & Graziela Silva Ferreira & Educação do corpo pela dança na escola. \\
\hline UFRN & Dissertação & 2013 & $\begin{array}{l}\text { Iracyara Maria } \\
\text { Assunção de Souza }\end{array}$ & $\begin{array}{l}\text { A aplicação dos temas transversais nas } \\
\text { aulas de Educação Física - ensino médio } \\
\text { integrado }\end{array}$ \\
\hline IFRS e & $\begin{array}{c}\text { Artigo } \\
\text { UFRGS }\end{array}$ & 2014 & $\begin{array}{c}\text { Eduardo Marczwski } \\
\text { da Silva e Alex } \\
\text { Branco Fraga }\end{array}$ & $\begin{array}{l}\text { A história da Educação Física na } \\
\text { Educação Profissional: entrada, saída e } \\
\text { retorno à Escola Federal de Porto Alegre }\end{array}$ \\
\hline UFRN & Dissertação & 2014 & $\begin{array}{c}\text { Marcos Antônio da } \\
\text { Silva }\end{array}$ & $\begin{array}{l}\text { Uma abordagem crítica do conteúdo } \\
\text { esporte nas aulas de Educação Física no } \\
\text { ensino médio integrado }\end{array}$ \\
\hline UFRN & Tese & 2014 & $\begin{array}{l}\text { Moysés de Souza } \\
\text { Filho }\end{array}$ & $\begin{array}{l}\text { Novas territorialidades pedagógicas para } \\
\text { identidade da Educação Física no } \\
\text { Ensino Médio integrado: } \\
\text { perspectiva pós-crítica }\end{array}$ \\
\hline UFF & Dissertação & 2015 & $\begin{array}{l}\text { A parlos Augusto } \\
\text { prática pedagógica do docente da } \\
\text { fisciplina Educação Física no Instituto } \\
\text { Federal Fluminense Campus Centro: } \\
\text { desvendando saberes e práticas }\end{array}$ \\
\hline
\end{tabular}




\begin{tabular}{|c|c|c|c|l|}
\hline UNIOESTE & Dissertação & 2015 & Tiago Amaral Silva & $\begin{array}{l}\text { A Educação Física no contexto dos } \\
\text { cursos de Educação Profissional Técnica } \\
\text { de Nível Médio Integrado do Instituto } \\
\text { Federal de Educação, Ciência e } \\
\text { Tecnologia de Mato Grosso do Sul }\end{array}$ \\
\hline UNESP & Tese & 2017 & $\begin{array}{l}\text { Juliano Daniel } \\
\text { Boscatto }\end{array}$ & $\begin{array}{l}\text { Proposta curricular para a Educação } \\
\text { Física no Instituto Federal de Santa } \\
\text { Catarina: uma construção colaborativa } \\
\text { virtual }\end{array}$ \\
\hline UFES & Dissertação & 2017 & $\begin{array}{l}\text { Fernanda Cristina } \\
\text { Merisio Fernandes } \\
\text { Soares. }\end{array}$ & $\begin{array}{l}\text { O currículo prescrito da Educação Física } \\
\text { num contexto de Ensino Médio integrado }\end{array}$ \\
\hline UNESP & Dissertação & 2018 & Fabiana Andreani & $\begin{array}{l}\text { O ensino da Educação Física no Instituto } \\
\text { Federal de São Paulo }\end{array}$ \\
\hline USP & Tese & 2019 & Kátia Regina de Sá & $\begin{array}{l}\text { Currículo do ensino médio integrado do } \\
\text { IFMG: a partitura, a polifonia e os solos } \\
\text { da Educação Física }\end{array}$ \\
\hline
\end{tabular}

Fonte: Elaborado pelos autores a partir dos estudos selecionados.

Com objetivo de investigar o percurso da EF no Instituto Federal de Santa CatarinaCampus São José, Cunha (2012) apresenta que a importância da EF para os estudantes do ensino médio integrado é de $57,37 \%$. O autor destaca que a EF incide pouco sobre a atuação profissional dos alunos trabalhadores investigados, não havendo relação dos conteúdos de ensino com as atividades laborais desempenhadas pelos estudantes. Tais conclusões indicam a necessidade de maior reflexão sobre o futuro desse componente curricular no ensino médio integrado, além de estudos que forneçam subsídios sobre as finalidades formalmente declaradas nos programas de ensino da $\mathrm{EF}$.

Souza (2013), professora de EF, apresenta em seu estudo uma proposta de trabalho pedagógico na EF do ensino médio integrado a partir de temas transversais (BRASIL, 1998). Através de uma pesquisa-ação, a autora se propõe a contribuir para a superação da ausência de estruturação dos temas transversais em articulação com a EF no Instituto Federal do Rio Grande do Norte (IFRN). Tal proposição apresenta as dificuldades no contexto do fazer pedagógico da EF, afirmando a ausência de sistematização dos conteúdos, dualidade entre teoria e prática e carência de planejamento curricular que atenda às propostas com temas transversais na instituição.

Souza (2013) apresenta a perspectiva de alinhamento entre EF e educação integrada, fundamentando-se na concepção de Chaves (2000) a respeito de formação integral. Chaves (2000) defende que o processo formativo deve englobar a formação do indivíduo, do cidadão e do profissional. Acrescenta-se a essa concepção os aportes teóricos em HildebrandtStramann (1986) através da concepção aberta de ensino e da teoria da ação dialógica de Freire (2012). Portanto, o objetivo principal desse estudo foi a configuração de uma concepção problematizadora das abordagens dos temas transversais numa intervenção pedagógica na $\mathrm{EF}$ do ensino médio integrado.

Destacam-se no estudo de Souza (2013) o princípio de totalidade curricular defendido por Libâneo (2004) e a proposta de educação integral dos Parâmetros Curriculares Nacionais PCNs (BRASIL, 1998), prevista enquanto aprendizagem e desenvolvimento cognitivo, psicomotor e socioafetivo. O currículo integrado (IFRN, 2009) também é contemplado através de um enfoque globalizador do conhecimento (ZABALLA, 2002). A interdisciplinaridade, utilizada na proposta de ação de Souza (2013), apresenta-se como princípio norteador de um 
ensino crítico (IFRN, 2009) e como abordagem facilitadora no ensino dos conteúdos da EF, em consonância com os temas transversais.

Ferreira (2013) analisa o ensino da dança no Instituto Federal de Educação, Ciência e Tecnologia da Bahia (IFBA) e se propõe a identificar e problematizar este conteúdo em suas relações epistemológicas com a EF do ensino médio integrado. Concebe a dança como área do conhecimento capaz de possibilitar aos alunos o exercício da cidadania, da consciência crítica, da autonomia e do potencial criativo. A partir das concepções de Castellani Filho (2002), Soares et al (2002), Bracht (1992), Gamboa (2007) e Santin (1987), Ferreira (2013) discorre sobre a natureza da EF enquanto prática pedagógica que tem por centralidade o movimento corporal ou movimento humano. Esse movimento, de maneira alguma, pode ser concebido fora de uma dinâmica histórico-cultural que o compreenda enquanto manifestação de um ser social (FERREIRA, 2013). Logo, sugere que os saberes que têm o corpo e o movimento e, consequentemente, a dança como possibilidade de conhecimento e de formação dos sujeitos, sejam contemplados na EF enquanto cultura corporal e enquanto arte.

Silva e Fraga (2014) apresentam um estudo sobre a história da EF no currículo da escola profissionalizante mais antiga de Porto Alegre. Após análise de documentos da instituição de ensino, dos anos de 1966 a 2012, avaliam que apenas a partir de 1970 esses documentos fazem referência à EF. Destacam importantes marcos legais, incluindo a Lei de Diretrizes e Bases da Educação Nacional (LDB) n 5.692 de 1971 (BRASIL, 1971b), o Decreto $\mathrm{n}^{\circ}$ 69.450/71 (BRASIL, 1971a) e a LDB n 9.394/96 (BRASIL, 1996). A LDB de 1971 (BRASIL, 1971b) reafirma a obrigatoriedade da EF enquanto "prática" em todas as instituições e níveis de ensino. Já o Decreto $n^{\circ}$ 69.450/71(BRASIL, 1971a) permite aos alunos dos cursos noturnos, que comprovem exercer jornada de trabalho igual ou superior a seis horas, a isenção das aulas de EF. A LDB 9.394/96 (BRASIL, 1996) apresenta a obrigatoriedade da disciplina apenas na educação básica (educação propedêutica), o que acaba por determinar na saída da EF do currículo da Escola Federal de Porto Alegre, no início dos anos 2000.

Silva e Fraga (2014) destacam que com o Decreto $n^{\circ}$ 5.154/04 (BRASIL, 2004), que estabelece a possibilidade de integração entre formação geral (de caráter propedêutico) e formação técnica profissionalizante, são apresentados os pressupostos de uma educação politécnica e unitária (SAVIANI, 2003a). Portanto, "a possibilidade de um ensino médio integrado reaproximou o ensino técnico profissionalizante do ensino médio regular" (SILVA; FRAGA, 2014, p. 268). Fato que favoreceu a reinserção da EF, em 2008, na Escola Federal de Porto Alegre. Em 2009, a Escola de Porto Alegre transforma-se em Campus Porto Alegre do Instituto Federal do Rio Grande do Sul (IFRS) e oferta o primeiro curso técnico integrado ao ensino médio.

Silva (2014) apresenta uma proposta de intervenção pedagógica de ensino do esporte na EF elaborada, planejada e executada com base em uma abordagem crítica de ensino (FREIRE, 2011; LIBÂNEO, 1994; LIBÂNEO, 2008). Também envolveu uma pesquisa-ação, na qual o pesquisador, professor do IFRN, desenvolveu sua proposta de abordagem do conteúdo esporte em suas dimensões conceituais, procedimentais e atitudinais. Os resultados obtidos após a execução de aulas planejadas confirmaram uma evolução e ampliação dos aspectos conceituais acerca do esporte, superando a visão reducionista do ensino de regras e de competição, ampliando a compreensão sociocultural dos alunos. Destacam-se as reflexões que o autor apresenta a respeito do esporte enquanto política, economia, trabalho e cultura. $\mathrm{O}$ que pressupõe que o ensino do esporte na escola, através de uma abordagem crítica, deve possibilitar atividades reflexivas e contextualizadas. 
O estudo de Souza Filho (2014) também se apresenta como importante contribuição para a organização curricular da EF do ensino médio integrado. Através de um diálogo com os educandos do IFRN, Souza Filho (2014) demonstra a importância de sua tese ao propor uma dimensão intercultural para a EF do ensino médio integrado, mediada por uma concepção pós-crítica do currículo. Esta concepção "rejeita as explicações óbvias e instituídas como verdades prontas no objetivo de regular e controlar os sujeitos da educação" (SOUZA FILHO, 2014, p. 7). "A teoria pós-crítica fundamenta seu discurso nas bases do pósestruturalismo e no multiculturalismo como um movimento ambíguo de adaptação e resistência (HOLLEBN, 2009 apud SOUZA FILHO, 2014, p. 91).

Ao fundamentar-se nos estudiosos das teorias pós-críticas (LOPES; MACEDO, 2010), Souza Filho (2014) esclarece que é necessário ampliar o debate das questões econômicas para os aspectos relacionados à sexualidade, etnia e ao gênero. Nesse sentido, afirma que a abordagem pós-crítica da EF ocupa espaço reduzido no campo de estudos, pesquisas e propostas pedagógicas curriculares. $\mathrm{O}$ autor considera a teoria pós-crítica uma concepção teórica capaz de integrar os saberes construídos no campo social da cultura corporal de movimento.

Boynard (2015) apresenta sua pesquisa com o objetivo de conhecer os saberes e as práticas dos docentes de EF no Instituto Federal Fluminense (IFF). Para tanto, analisa as limitações e potencialidades vivenciadas por esses docentes no processo de ensino aprendizagem e compromete-se em contribuir com a reorientação de suas práticas pedagógicas, priorizando as metodologias ativas. Sua pesquisa foi realizada com 13 professores de EF do IFF de Campos dos Goyatazes - Unidade Centro, que atuavam há pelo menos 10 anos no ensino médio integrado. Boynard (2015) desenvolveu um programa de capacitação, reciclagem e atualização dos docentes.

Diante da necessidade de reformulação de conteúdos programáticos da $\mathrm{EF}$, para melhor atender ao projeto de ensino médio integrado, Boynard (2015) apresenta as proposições de Daolio (1986), Verenguer (1995) e Pereira e Silva (2004). Daolio (2002) afirma que a EF do ensino médio deve promover atividades pessoais em contrapartida ao trabalho, como atividades de relaxamento, permitindo ao adolescente perceber e controlar seu próprio corpo. Verenguer (1995) concebe as atividades corporais como oportunidade de os alunos pensarem suas potencialidades motoras e a influência que recebem do contexto social. Pereira e Silva (2004) compreendem as práticas pedagógicas na EF a partir de práticas motoras fundamentais e associadas com as práticas cognitivas, incluindo temas em saúde, ética, aptidão, qualidade de vida e promoção do pensamento crítico. Logo, esse conjunto de práticas deve vincular-se às questões biológicas, sociais, econômicas, políticas e históricas.

Silva (2015) desenvolveu sua dissertação de mestrado com o objetivo de analisar a EF no contexto dos cursos técnicos integrados de nível médio do Instituto Federal do Mato Grosso do Sul (IFMT). Ao problematizar a finalidade e organização da EF enquanto componente curricular, discute a possibilidade de rompimento dos moldes tradicionais de ensino da EF. No entanto, o autor conclui que a EF ainda está distante de uma perspectiva de integração curricular, de uma educação politécnica e omnilateral. Sua fundamentação teórica partiu do processo de consolidação histórica da Educação Profissional e dos Institutos Federais no Brasil, chegando às teorias pedagógicas que influenciaram a EF escolar.

Com relação às teorias pedagógicas da EF, há amplo destaque para as teorias críticas e suas contribuições na construção do currículo da disciplina. Para Silva (2015), as tendências crítico-superadora e crítico-emancipatória reconhecem todos os elementos da cultura corporal de movimento como parte de "uma totalidade no processo de construção do currículo da educação física escolar dentro da educação profissional técnica de nível médio integrado" 
(SILVA, 2015, p. 97). Confirma-se o caráter plural da área do conhecimento que fundamenta a EF escolar e as múltiplas possibilidades teóricas e práticas desse componente curricular. No entanto, Silva (2015) defende que a preparação de corpos e mentes para atenderem ao mercado de trabalho ainda é uma máxima. A formação de trabalhadores livres, reflexivos e autônomos deve ser a centralidade das ações pedagógicas e do currículo (SILVA, 2015).

Boscatto (2017) desenvolve uma proposta curricular da EF do ensino médio integrado em um Instituto Federal de Santa Catarina (IFSC), a partir da análise de uma construção colaborativa virtual que envolveu seis docentes de EF. Como parte dessa proposta, apresenta os temas articuladores dos conhecimentos da EF: saúde, corpo e trabalho, violência, preconceitos e discriminação social, tecnologias de informação, cultura digital e nutrição. Esses temas seriam desenvolvidos em articulação com os conhecimentos referentes à cultura corporal de movimento.

Boscatto (2017) apresenta importantes reflexões a respeito da articulação da EF com a EPT. Compreende que as especificidades dos conhecimentos na área devem promover a análise crítica sobre o modo de produção no âmbito do emprego, além dos aspectos relacionados ao lazer e à saúde do trabalhador. Assim, "os elementos que cercam as relações entre "corpo" e "trabalho" são indispensáveis à formação dos estudantes da EPT" (BOSCATTO, 2017, p. 100).

Soares (2017) busca compreender o lugar da EF nos cursos técnicos integrados do Instituto Federal do Espírito Santo (IFES). Ao analisar os planos de ensino, identifica as concepções e focos de ensino das práticas pedagógicas. A autora apresenta uma contextualização histórica e conceitual do ensino médio e do ensino médio integrado, a fim de elucidar para o leitor o locus de sua pesquisa. Para tanto, aborda a concepção de educação em sua dualidade histórica (FRIGOTTO, 2007; MOURA, 2007) e destaca o enfoque que as Diretrizes Curriculares (BRASIL, 2013) e Ramos (2008) dão à EPT. Com relação à oferta de uma formação para o trabalho, a EPT ocupa um lugar de tensões, de críticas, de avanços e de retrocessos (RAMOS, 2008). A EPT deve priorizar a formação integral do indivíduo (CIAVATTA, 2005), oferecendo condições para a superação da divisão social do trabalho, a saber, a do trabalho intelectual versus trabalho manual.

Através das proposições de Gariglio (2001), Soares (2017) relaciona a relevância da EF para a formação do trabalhador por meio do desenvolvimento de saberes e capacidades para a melhoria das condições de trabalho no interior das fábricas. O conceito de saúde, nesse sentido, desvelaria as relações existentes entre os universos do trabalho, do lazer e da saúde. Tais relações, ao serem abordadas nas aulas de EF, devem desmistificar a proposta de atividade física por parte de empresas como garantia de saúde do trabalhador. O que implica conceber as demais condições agregadas a esta, como salários e alimentação adequados, moradia, acesso à saúde, ao lazer e demais bens de cidadania (SOARES, 2017).

Com o objetivo de analisar o ensino da EF no Instituto Federal de São Paulo (IFSP), Andreani (2018) apresenta algumas dificuldades específicas da EF no contexto do ensino médio integrado. A ausência de integração desse componente com a parte técnica dos cursos, a "cultura das dispensas" nas aulas, o desinteresse pelas atividades corporais desenvolvidas na escola, as preocupações com vestibulares e inserção no mercado de trabalho foram alguns aspectos elencados nessa análise (ANDREANI, 2018). Ao relacionar o percurso da EF nos Institutos Federais, Andreani (2018) também apresenta a relação da EF com a categoria trabalho. Assim, a autora traz o embate que se refere à concepção da EF enquanto possibilidade de melhoria da performance do trabalhador. Essa concepção justificaria o discurso hegemônico, historicamente construído, que defende a EF enquanto prática corporal 
com o potencial de atuar sobre a saúde do trabalhador, ou seja, do indivíduo disciplinado e moralmente pronto a atender às demandas produtivas (GARIGLIO, 1997).

Sá (2019) analisa o currículo do ensino médio integrado do Instituto de Educação, Ciência e Tecnologia de Minas Gerais (IFMG), bem como sua relação com a Educação em Tempo Integral e a construção curricular do componente EF. Sua pesquisa revela que o currículo do IFMG é permeado pelo discurso neoliberal. Nesse sentido, os currículos expressam a falta de integração curricular e a tendência em se curvarem aos discursos hegemônicos por meio das relações de poder (SÁ, 2019). Através de uma abordagem macro, meso e micro das propostas curriculares, Sá (2019) afirma que o currículo não contempla as múltiplas dimensões da formação humana. A jornada extenuante e o excesso de tarefas seriam indicadores negativos advindos dessa organização curricular. O estímulo à autonomia, a valorização da identidade e de rede de saberes, sintonizados às questões cotidianas da vida, se evidenciaram como aspectos positivos.

Quanto à EF e sua contextualização na EPT, Sá (2019) apresenta um panorama histórico-conceitual da Educação Profissional a partir de Marx e Gramsci. Os conceitos de escola unitária (GRAMSCI, 2004), politecnia (SAVIANI, 2003b) e currículo integrado (CIAVATTA; RAMOS, 2012) aparecem enquanto nortes para a atual configuração do ensino médio integrado nos Institutos Federais. Diante desses conceitos, ressalta-se a aproximação da EF escolar aos ideais de sociedade capitalista. São apresentadas as visões de corpo "produtivo", corpo "saudável", corpo "deserotizado", corpo "dócil" que fundamentou as práticas corporais na escola (BRACHT, 1999). A aproximação da EF às perspectivas da "vida moderna" também esteve permeada pela ideia de eficiência, a fím de atender às novas exigências do trabalho produtivo industrial a partir da década de 20 (VAGO, 2004).

Em suma, as propostas curriculares da EF estariam permeadas de resquícios de teorias acríticas, revelando o papel contra hegemônico das novas propostas críticas e pós-críticas no contexto de uma formação verdadeiramente integral e integrada (SÁ, 2019). Sá (2019) destaca que no campo da EPT é perceptível a influência das teorias críticas, principalmente nos Institutos Federais. Porém, a dualidade entre formação geral e formação para o trabalho ainda insiste em coexistir com os discursos neoliberais que rondam os currículos na EPT.

\section{Temáticas abordadas nas publicações científicas}

As publicações científicas selecionadas apresentaram algumas temáticas em comum relacionadas em seus estudos e outras que não apresentaram similaridade. Elas se referem ao histórico da Educação Profissional (EP) dos Institutos Federais (IFs) em estudo, ao histórico da EF e sua relação com a EPT, à análise da EF na dinâmica curricular e às propostas de práticas pedagógicas para o ensino médio integrado (EMI). Tais temáticas estão relacionadas aos estudos conforme a Tabela 1.

Tabela 1 - Temáticas abordadas nas publicações científicas

\begin{tabular}{lcccc}
\hline \multicolumn{1}{c}{ Autor/ano } & $\begin{array}{c}\text { Histórico da } \\
\text { EP nos IFs }\end{array}$ & $\begin{array}{c}\text { Histórico da } \\
\text { EF/Relações } \\
\text { com } \\
\text { a EPT }\end{array}$ & $\begin{array}{c}\text { Proposta de } \\
\text { Prática } \\
\text { Pedagógica } \\
\text { na EF }\end{array}$ & $\begin{array}{c}\text { Análise da EF no } \\
\text { Currículo/PPP/Pla } \\
\text { no de Ensino no } \\
\text { EMI }\end{array}$ \\
\hline CUNHA, 2012. & $\mathrm{X}$ & $\mathrm{X}$ & & $\mathrm{X}$ \\
\hline FERREIRA, 2013. & & $\mathrm{X}$ & & $\mathrm{X}$ \\
SOUZA, 2013. & $\mathrm{X}$ & $\mathrm{X}$ & $\mathrm{X}$ & $\mathrm{X}$ \\
SILVA; FRAGA, 2014. & & & $\mathrm{X}$ & \\
\hline SILVA, 2014. & & & & \\
\hline
\end{tabular}


Revista de Educação, Ciência e Tecnologia

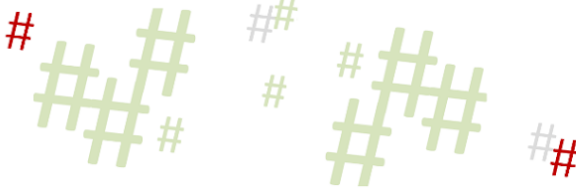

\begin{tabular}{|c|c|c|c|c|}
\hline SOUZA FILHO, 2014. & & $X$ & $X$ & $X$ \\
\hline SILVA, 2015. & $\mathrm{X}$ & $\mathrm{X}$ & & $\mathrm{X}$ \\
\hline BOYNARD, 2015. & $\mathrm{X}$ & $\mathrm{X}$ & & $\mathrm{X}$ \\
\hline BOSCATTO, 2017. & $\mathrm{X}$ & $\mathrm{X}$ & & $\mathrm{X}$ \\
\hline SOARES, 2017. & $\mathrm{X}$ & $\mathrm{X}$ & & $\mathrm{X}$ \\
\hline ANDREANI, 2018. & $\mathrm{X}$ & $\mathrm{X}$ & & $\mathrm{X}$ \\
\hline SÁ, 2019. & $X$ & $\mathrm{X}$ & & $\mathrm{X}$ \\
\hline
\end{tabular}

Legenda: EP-Educação Profissional; IFs-Institutos Federais; EF-Educação Física; EPT-Educação Profissional e Tecnológica; PPP-Projeto Político-pedagógico; EMI-Ensino Médio Integrado.

Fonte: Elaborado pelos autores com base nos dados da pesquisa.

\section{Caracterização da Educação Física do ensino médio integrado}

A respeito da $\mathrm{EF}$ e suas características, perspectivas, potencialidades e dificuldades, os estudos revelaram aspectos convergentes, mas também dissonantes. Alguns estudos contribuíram para a caracterização da EF no contexto de alguns Institutos Federais, especificamente no ensino médio integrado. As principais reflexões, análises e perspectivas dos autores estão organizadas conforme o Quadro 2, permitindo uma análise abrangente com relação ao contexto desse componente curricular em nove Institutos Federais do Brasil.

Quadro 2 - Caracterização da Educação Física do ensino médio integrado (EMI)

\begin{tabular}{|c|c|}
\hline Instituto Federal & Caracterização da Educação Física (EF) \\
\hline IFSP & $\begin{array}{l}\text { A EF apresenta traços de concepções tradicionais de ensino: pouco planejamento } \\
\text { participativo e necessidade de maior diversidade de metodologias de ensino e } \\
\text { critérios avaliativos nas dimensões conceitual, procedimental e atitudinal; } \\
\text { Componente curricular desprestigiado: em alguns campi não está presente em todos } \\
\text { os anos do EMI ou a sua oferta é optativa. Restrito número de aulas, } \\
\text { comprometimento do espaço físico e de materiais pedagógicos; } \\
\text { Principais finalidades: formação do cidadão crítico (através da problematização das } \\
\text { questões sociais) e promoção da saúde; } \\
\text { Objeto de estudo: a cultura corporal de movimento (jogos, esportes, danças, lutas, } \\
\text { ginásticas e práticas corporais de aventura); } \\
\text { Predominância do conteúdo de esporte e valorização dos esportes pouco conhecidos } \\
\text { no Brasil; } \\
\text { A EF está presente em todos os cursos de EMI; } \\
\text { Aulas teóricas e práticas; } \\
\text { Conhecimentos críticos a serem abordados na EF: problematização de questões } \\
\text { sociais; } \\
\text { A EF está distante da área técnica dos cursos. }\end{array}$ \\
\hline IFF & $\begin{array}{l}\text { Os conteúdos programáticos da EF pouco atendem às demandas emergentes como } \\
\text { temas interdisciplinares, transdisciplinares e a diversificação dos conteúdos; } \\
\text { Aulas teóricas e práticas; } \\
\text { Estrutura física adequada ao processo de ensino-aprendizagem na EF; } \\
\text { Professores comprometidos com a superação do ensino transmissivo; } \\
\text { Prática docente comprometida com a promoção da saúde e da qualidade de vida; } \\
\text { A EF é valorizada através de projetos institucionais: treinamento esportivo, aulas de } \\
\text { musculação, aulas de pilates, clube do xadrez e clube do tênis de mesa. }\end{array}$ \\
\hline IFSC & $\begin{array}{l}\text { Relação forte com os "conhecimentos sobre o corpo"; } \\
\text { Relaciona as contribuições para a vida, para o exercício da cidadania e compreensão } \\
\text { do contexto sociocultural; } \\
\text { Concebe as relações entre "corpo" e "trabalho"; } \\
\text { Diversificação de conteúdos; } \\
\text { Perspectiva crítica de ensino. }\end{array}$ \\
\hline IFBA & $\begin{array}{l}\text { A EF não contempla a dança enquanto arte; } \\
\text { A EF não tem a dança como elemento central; }\end{array}$ \\
\hline
\end{tabular}




\begin{tabular}{|c|c|}
\hline & $\begin{array}{l}\text { A EF contempla a dança enquanto conteúdo e cultura corporal de movimento; } \\
\text { A EF, juntamente com o componente curricular Artes, tem o corpo e o movimento } \\
\text { como produto e produtor de seus saberes e é responsável pela produção do } \\
\text { conhecimento em dança na instituição. }\end{array}$ \\
\hline IFMG & $\begin{array}{l}\text { Currículo da EF com maior centralidade na cultura e influência do currículo } \\
\text { esportivista e do currículo saudável; } \\
\text { A EF busca legitimação e é alvo constante de ameaças enquanto componente } \\
\text { curricular: carga horária reduzida em alguns cursos do EMI, desarticulação com o } \\
\text { Projeto Político Pedagógico (PPC) e dificuldades na infraestrutura para as aulas; } \\
\text { A EF não dialoga com as perspectivas de formação para o trabalho, pois os } \\
\text { professores relatam que ainda precisam avançar nesse aspecto em suas práticas } \\
\text { pedagógicas; } \\
\text { As propostas pedagógicas dos professores de EF estão desalinhadas com os Projetos } \\
\text { Políticos de Cursos (PPCs); } \\
\text { Associação da EF à promoção de saúde; } \\
\text { Apropriação da cultura corporal de movimento. }\end{array}$ \\
\hline IFRS & $\begin{array}{l}\text { A EF está presente, com carga horária semanal de uma hora nos dois primeiros } \\
\text { semestres, no curso técnico integrado ao ensino médio na modalidade do Programa } \\
\text { Nacional de Integração da Educação Profissional com a Educação Básica, na } \\
\text { Modalidade de Jovens e Adultos (PROEJA) - Câmpus Porto Alegre; } \\
\text { Aulas predominantemente teóricas; } \\
\text { Conteúdos de ergonomia e educação postural são os mais explicitados; } \\
\text { Os conteúdos parecem estar mais ajustados à proposta profissionalizante do que } \\
\text { com a tradição propedêutica da EF. }\end{array}$ \\
\hline IFMT & $\begin{array}{l}\text { Hegemonia do esporte como principal conteúdo da EF; } \\
\text { Indícios de busca pela superação das concepções biologicista, tecnicista e } \\
\text { esportivista da EF; } \\
\text { A principal orientação para a prática pedagógica na EF parte das ementas dos PPCs; } \\
\text { Presença de proposições de práticas construtivistas, interdisciplinares e que } \\
\text { relacionem o mundo do trabalho; } \\
\text { Carência de planejamento coletivo e de projetos de pesquisa e extensão para a } \\
\text { integração curricular envolvendo a EF. }\end{array}$ \\
\hline IFES & $\begin{array}{l}\text { Diferentes perspectivas de ensino na EF: abordagem crítica, abordagem dos } \\
\text { parâmetros curriculares, abordagem esportivista, abordagem da saúde renovada; } \\
\text { Maior proximidade com abordagens críticas; } \\
\text { Abordagens de conteúdos para além do esporte, da ginástica, da dança, dos jogos, } \\
\text { atividades rítmicas e expressivas e conhecimento sobre corpo humano; } \\
\text { As práticas pedagógicas na EF incluem a compreensão e discussão a respeito de } \\
\text { valores, sentidos e significados das práticas corporais e da dimensão da formação } \\
\text { profissional. }\end{array}$ \\
\hline IFRN & $\begin{array}{l}\text { A EF não apresenta clareza de sua intencionalidade pedagógica; } \\
\text { As práticas pedagógicas priorizam conteúdos no contexto prático, ou seja, do } \\
\text { "saber-fazer"; } \\
\text { Historicamente, a EF não construiu uma identidade de prática pedagógica com } \\
\text { saberes sistematizados; } \\
\text { Ausência de planejamento de ensino; } \\
\text { A EF não contempla a introdução de temas transversais. }\end{array}$ \\
\hline
\end{tabular}

Fonte: Elaborado pelos autores com base nos dados das pesquisas de Andreani (2018); Cunha (2012); Boynard (2015); Ferreira (2013); Sá (2019); Silva e Fraga (2014); Silva (2015); Soares (2017); Souza (2013).

Em três estudos não foi possível realizar a análise anterior. Boscatto (2017) apresenta a caracterização da EF no EMI de forma geral, sem tecer investigações específicas ao currículo do IFSC, apesar de apresentar uma proposta de organização curricular para o Instituto. O estudo de Marcos Antônio da Silva (2014) não relacionou características da disciplina no Campus Pau de Ferros - IFRN, apresentando uma proposta de intervenção pedagógica no ensino do esporte. Souza Filho (2014), apesar de realizar seu estudo no IFRN Campus Natal Zona Norte, não investigou características da disciplina relacionadas ao 
Instituto, especificamente. Por esta razão, não foi possível apontar características da disciplina a partir dos estudos destes autores e dos respectivos Institutos Federais.

Diante da contextualização histórica apresentada nas publicações científicas analisadas, foi possível verificar que a EF do ensino médio integrado é desafiada constantemente a romper com a barreira da alienação e distanciamento entre a teoria e a prática. Como bem constatou Boscatto e Darido (2017), a produção do conhecimento no campo da EF abrange tanto a análise de temáticas da subárea pedagógica quanto os aspectos inerentes ao currículo escolar. Estudos abrangentes a respeito do currículo da EF do ensino médio, de caráter exclusivamente propedêutico, revelam a necessidade de sistematização ou organização dos saberes curriculares que norteiam as práticas de ensino da EF (ALMEIDA, FENSTERSEIFER, 2014; MATOS et al, 2015). Essa condição também se reafirma no contexto do ensino médio integrado, uma vez que a investigação aqui apresentada revela posicionamentos teóricos com diferentes perspectivas epistemológicas. A produção teórica do conhecimento na área ainda está distante das práticas de ensino dos professores vinculados aos Institutos Federais e de uma efetiva materialização dos pressupostos que se referem ao currículo integrado.

No entanto, há avanços importantes na construção do diálogo pedagógico. Há potencialidades reais de construção de um currículo comprometido com a superação do caráter esportivista e procedimental das práticas de ensino. Para tanto, a aproximação entre as produções científicas e a prática docente é primordial. Boscatto e Darido (2017) sugerem que haja diálogo colaborativo entre os protagonistas das ações educativas cotidianas, a saber, entre os professores que estão no "chão da escola" (BOSCATTO; DARIDO, 2017, p. 14). São esses professores que denunciam as fragilidades, entraves e obstáculos reais de articulação entre currículo integrado e prática docente. Nesse contexto, podemos destacar a apropriação equivocada dos discursos hegemônicos para sustentar a legitimidade da EF no currículo integrado. As lutas de poder, às quais Arroyo (2011), Ciavatta (2016) e Frigotto (2009) se referem, estão explícitas na dinâmica social e afetam diretamente a construção do currículo escolar, a identidade docente e discente em todas as esferas de ensino. Portanto, podemos ponderar que a diversidade de culturas, saberes, valores e leituras de mundo ajudam a compreender tamanha diversidade de conteúdos, organização curricular e concepções de ensino na EF do ensino médio integrado.

\section{Considerações finais}

A partir da descrição das publicações científicas envolvendo a temática da EF do ensino médio integrado, foi possível observar que elas estiveram concentradas nas regiões nordeste, sudeste e sul do Brasil. Tais pesquisas concentram-se em refletir aspectos relacionados à organização curricular e às teorias pedagógicas da $\mathrm{EF}$, com enfoque para as concepções críticas. Portanto, as tendências crítico-superadora e crítico-emancipatória são apontadas como concepções teóricas adequadas aos projetos do ensino médio integrado, juntamente com a concepção aberta de ensino, a teoria da ação dialógica e as teorias póscríticas.

Observou-se, em todas as publicações, dificuldades quanto à materialização de práticas integradoras no ensino médio envolvendo a EF. Podemos destacar a escassez de referências a projetos integradores e de práticas interdisciplinares. Apenas o estudo de Souza (2013) apresentou propostas didático-pedagógicas de caráter interdisciplinar, confirmando que elas facilitam o processo de ensino-aprendizagem numa perspectiva de educação integral e integrada. Há também subsídios para inferir que a EF permanece distante da parte técnica dos currículos. A baixa quantidade de produção científica pode levar ao entendimento da 
necessidade de maior discussão e pesquisa em relação à temática. Por isso, sugerimos que as pesquisas futuras apresentem propostas didático-pedagógicas que contribuam com a prática docente na EF do ensino médio integrado.

Também ressaltamos a relevância dos estudos que defendem a reestruturação do currículo integrado e a necessidade de aprofundamento das proposições pedagógicas com foco na formação omnilateral dos estudantes. Ao centrarem-se nos princípios da integração dos conhecimentos e de totalidade curricular, ações com enfoque na interdisciplinaridade, na transdisciplinaridade ou na multidisciplinaridade podem fortalecer a integração da EF com os demais componentes curriculares, além de estimular as múltiplas vivências da cultura corporal de movimento e sua contextualização com as temáticas relevantes para a formação integral dos estudantes de nível médio técnico. A partir dos nossos achados, consideramos que este estudo pode subsidiar futuras pesquisas relacionadas ao ensino da EF do ensino médio integrado. Como principal limitação de nosso estudo, destacamos que ele não reúne todo corpo de evidências científicas, uma vez que a utilização de apenas duas bases de dados pode excluir publicações relevantes. Além disso, nosso estudo não cumpriu com todos os requisitos de uma revisão sistemática.

\section{Referências}

ALMEIDA, Eliane Maria de; MARTINELI, Telma Adriana Pacífico. Apropriações da teoria histórico-cultural na educação física. Pro-Posições, v. 29, n. 3, p. 383-400, 2018. Disponível em:

$<$ https://www.scielo.br/scielo.php?pid=S010373072018000300383\&script=sci_abstract\&tlng $=\mathrm{pt}>$. Acesso em: $22 \mathrm{dez} .2019$.

ALMEIDA, Felipe Quintão; BRACHT, Valter; VAZ, Alexandre. Classificações epistemológicas na educação física: redescrições... Movimento, v. 18, n. 4, p. 241-263, 2012. Disponível em: <https://seer.ufrgs.br/Movimento/article/view/27727>. Acesso em: 22 dez. 2019.

ALMEIDA, Luciano de; FENSTERSEIFER, Paulo Evaldo. A relação teoria-prática na educação física escolar: desdobramentos para pensar um "programa mínimo". Revista Kinesis, Santa Maria, ed. 32 v. 2, 2014.

ANDREANI, Fabiana. O ensino da educação física no Instituto Federal de São Paulo. Bauru: UNESP, 2018. 249 p. DISSERTAÇÃO (Mestrado Profissional em Docência para Educação Básica): Universidade Estadual Paulista, 2018.

ARROYO, M. G. Currículo, território em disputa. 2 ed. Petrópolis, RJ: Vozes, 2011.

BRACHT, Valter. A constituição das teorias pedagógicas da educação física. Cadernos Cedes, Campinas, v. XIX, n. 48, p. 69-88, 1999. Disponível em: <http://www.scielo.br/pdf/ccedes/v19n48/v1948a05.pdf>. Acesso em: 18 dez. 2019.

BRACHT, Valter. Aprendizagem social e educação física. Porto Alegre: Magister, 1992.

BRACHT, Valter. Educação física e aprendizagem social. 2. ed. Porto Alegre: Magister, 1997. 
Revista de Educação, Ciência e Tecnologia
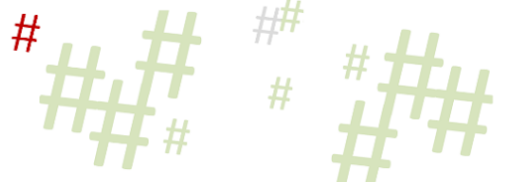

BRASIL. Decreto no 2.208, de 17 de abril de 1997. Regulamenta o $§ 2^{\circ}$ do art. 36 e os arts. 39 a 42 da Lei $n^{\circ} 9.394$, de 20 de dezembro de 1996, que estabelece as diretrizes e bases da educação nacional. Brasília, DF: 17 de abril de 1997. Disponível em: <https://www.planalto.gov.br/ccivil03/decreto/D2208.htm>. Acesso em:18 out. 2019.

BRASIL. Decreto ${ }^{\circ} \mathbf{5 . 1 5 4}$, de 23 de julho de 2004. Regulamenta o $\S 2^{\circ}$ do art. 36 e os arts. 39 a 41 da Lei n. 9.394, de 20 de dezembro de 1996, que estabelece as diretrizes e bases da educação nacional, e dá outras providências. Diário Oficial da União, Brasília/DF, 2004.

BRASIL. Decreto ${ }^{\circ}$ 69.450, de 1 de novembro de 1971. Regulamenta o artigo 22 da Lei número 4.024, de 20 de dezembro de 1961, e alínea c do artigo 40 da Lei 5.540, de 28 de novembro de 1968 e dá outras providências. Diário Oficial da União, Brasília/DF, 1971(a).

BRASIL. Ministério da Educação. Diretrizes Curriculares Nacionais da Educação Básica. Brasília: MEC, 2013.

BRASIL. Ministério de Educação e do Desporto. Secretaria de Educação Fundamental. Parâmetros Curriculares Nacionais. Brasília: MEC/SEF, 1998.

BRASIL. Presidência da República. Lei n 5.692, de 11 de agosto de 1971 . Fixa diretrizes e bases para o ensino de $1^{\circ}$ e $2^{\circ}$ graus, e dá outras providências. Diário Oficial da União, Brasília/DF, 1971 (b).

BRASIL. Presidência da República. Lei no 11.892 de 29 de dezembro de 2008. Institui a Rede Federal de Educação Profissional, Científica e Tecnológica, cria os Institutos Federais de Educação, Ciência e Tecnologia, e dá outras providências. Brasília/DF: Presidência da República, 2008. Disponível em: <http://www.planalto.gov.br/ccivil_03/_ato20072010/2008/lei/111892.htm>. Acesso em: 20 nov. 2019.

BOSCATTO, Juliano Daniel; DARIDO, Suraya Cristina. Currículo e educação física escolar: análise do estado da arte em periódicos nacionais. Journal of Physical Education, v. 28, e2855, p. 1-16, 2017. Disponível em https://www.scielo.br/pdf/jpe/v28/2448-2455-jpe-28e2855.pdf. Acesso em: 15 dez. 2019.

BOSCATTO, Juliano Daniel. Proposta curricular para a educação física no Instituto Federal de Santa Catarina: uma proposta colaborativa virtual. Rio Claro: UNESP, 2017. 164 p. TESE (Doutorado em Desenvolvimento Humano e Tecnologias): Universidade Estadual Paulista, 2017.

BOYNARD, Carlos Augusto Sanguedo. A prática pedagógica do docente da disciplina educação física no Instituto Federal Fluminense Campus Centro: desvendando saberes e práticas. Niterói: UFF, 2015. 114 p. DISSERTAÇÃO (Mestrado Profissional em Ensino na Saúde): Universidade Federal Fluminense, 2015.

CASTELLANI FILHO, Lino. Política educacional e educação física. 2ed. Campinas: Autores Associados, 2002.

CHAVES, Eduardo O. C. Educação, Temas Transversais e Tecnologia. In: LOMBARDI, José Claudinei. (Org.) Pesquisa em educação: História, Filosofia e Temas Transversais. 2 ed. Campinas SP: Autores Associados: HISTERDBR; Caçador, SC: UnC, 2000. 
CIAVATTA, Maria. A formação integrada a escola e o trabalho como lugares de memória e de identidade. Trabalho Necessário, v. 3, n. 3, p. 1-20, 2005. Disponível em:

https://periodicos.uff.br/trabalhonecessario/article/view/6122/5087 Acesso em: 15 dez. 2019.

CIAVATTA, Maria. A produção do conhecimento sobre a configuração do campo da educação profissional e tecnológica. Holos, v. 6, p. 33-49, 2016. Disponível em:

http://www2.ifrn.edu.br/ojs/index.php/HOLOS/article/view/5013>. Acesso em 15 dez. 2019.

CIAVATTA, Maria.; RAMOS, Marise. A “era das diretrizes": a disputa pelo projeto de educação dos mais pobres. Revista Brasileira de Educação, v. 17, n. 49, p. 11-37, 2012. Disponível em: <https://www.scielo.br/scielo.php?pid=S1413-

$24782012000100002 \&$ script=sci_abstract\&tlng=pt>. Acesso em: 15 dez. 2019.

CUNHA, Marcílio Lourenço. O percurso da educação física no Instituto Federal de Santa Catarina-Campus São José. Campinas: UNICAMP, 2012. 85 p. DISSERTAÇÃO (Mestrado em Educação): Universidade Estadual de Campinas, 2012.

DAOLIO, Jocimar. A cultura da/na educação física. 2002. 112 f. TESE (Livre Docência): Faculdade de Educação Física, Universidade Estadual de Campinas, Campinas, 2002.

DAOLIO, Jocimar. A importância da educação física para o adolescente que trabalha: uma abordagem psicológica. Revista Brasileira de Ciências do Esporte, Campinas, v.8, n.1, p.134-138, 1986.

DAOLIO, Jocimar. Da cultura do corpo. Campinas, SP: Papirus, 1994.

FENSTERSEIFER, Paulo Evaldo. Produção do conhecimento em Educação Física: algumas reflexões a partir do Brasil. Educación Física y Ciencia, v. 17, n. 2, p. 1-7, 2015. Disponível em: <https://www.efyc.fahce.unlp.edu.ar/article/view/EFyCv17n02a03/6946>. Acesso em: 23 $\operatorname{dez} 2019$.

FERREIRA, Graziela Silva. Educação do corpo pela dança na escola profissionalizante: o contexto do Instituto Federal de Educação, Ciência e Tecnologia da Bahia. Salvador: UFBA, 2013. 170 p. DISSERTAÇÃO (Mestrado em Dança): Universidade Federal da Bahia, 2013.

FERREIRA, Norma Sandra de Almeida. As pesquisas denominadas "estado da arte".

Educação \& Sociedade, v. 23, n. 79, p. 257-272, 2002. Disponível em:

$<$ https://www.scielo.br/scielo.php?pid=s0101-

73302002000300013\&script=sci_abstract\&tlng=pt>. Acesso em: 19 nov. 2019.

FREIRE, Paulo. Pedagogia da autonomia: saberes necessários a prática educativa. São Paulo: Paz e Terra, 2011.

FREIRE, Paulo. Pedagogia do oprimido. Ed. Especial. Rio de Janeiro: Nova Fronteira, 2012.

FRIGOTTO, Gaudêncio. A interdisciplinaridade como necessidade e como problema nas ciências sociais. Revista do Centro de Educação e Letras da UNIOESTE, v. 10, p. 41-62, 2008. Disponível em: 〈http://e-revista.unioeste.br/index.php/ideacao/article/view/4143> Acesso em: 16 dez. 2019. 
Revista de Educação, Ciência e Tecnologia

FRIGOTTO, Gaudêncio. A relação da educação profissional e tecnológica com a universalização da educação básica. Educação e Sociedade, v. 28, n. 100, p. 1129-1152, 2007. Disponível em: <https://www.scielo.br/pdf/es/v28n100/a2328100.pdf >. Acesso em: 16 dez. 2019.

FRIGOTTO, Gaudêncio. Teoria e práxis e o antagonismo entre a formação politécnica e as relações sociais capitalistas. Trabalho, Educação e Saúde, v. 7, p. 67-82, 2009. Disponível em <https://www.scielo.br/pdf/tes/v7s1/04.pdf>. Acesso em: 10 out. 2020.

GAMBOA, Silvio Sánchez. Epistemologia da educação física: as inter-relações necessárias. Maceió: EDUFAL, 2007.

GARIGLIO, José Ângelo. A Proposta de ensino de Educação Física para uma escola profissionalizante: uma experiência no CEFET-MG. In: Francisco Eduardo Caparróz (Org.). Educação Física Escolar: política, investigação e intervenção. Vitória: Proteoria, 2001. p. 39-65.

GARIGLIO. José Ângelo. O ensino da educação física nas engrenagens de uma escola profissionalizante. Belo Horizonte: UFMG, 1997. DISSERTAÇÃO (Mestrado em Educação). Universidade Federal de Minas Gerais, 1997.

GRAMSCI, Antônio. Caderno 12. Apontamentos e notas dispersas para um grupo de ensaios sobre história dos intelectuais. In: GRAMSCI, Antônio. Caderno do Cárcere. 3. ed. Rio de Janeiro: Civilização Brasileira, 2004. p. 15-53.

HENRIQUE, Ana Lúcia Sarmento; NASCIMENTO, José Mateus do. Sobre práticas integradoras: um estudo de ações pedagógicas na educação básica. Holos, ano 31, v. 4, p. 6376, 2015. Disponível em <http://www2.ifrn.edu.br/ojs/index.php/HOLOS/article/view/3188>. Acesso em: 15 dez. 2019.

HILDEBRANDT -STRAMANN, Reiner. Concepções abertas no ensino da educação física. Rio de Janeiro: Ao Livro Técnico, 1986.

INSTITUTO FEDERAL DE EDUCAÇÃO, CIÊNCIA E TECNOLOGIA DO RIO GRANDE DO NORTE, Projeto político-pedagógico: uma construção coletiva. Documento base, 2009.

KUNZ, Elenor. Transformação didático-pedagógica do esporte. Ijuí: Unijuí, 1994.

LIBÂNEO, José Carlos. Democratização da escola pública: a pedagogia crítico social dos conteúdos. 22 ed. São Paulo: Edições Loyola, 2008.

LIBÂNEO, José Carlos. Didática. São Paulo: Cortez, 1994.

LIBÂNEO, José Carlos. O planejamento escolar e o projeto pedagógico-curricular. In: LIBÂNEO, José Carlos (Org.). Organização e gestão escolar: teoria e prática. 5. ed. Goiânia: Editora Alternativa, 2004.

LOPES, Alice Casimiro; MACEDO, Elizabeth (Orgs.). O pensamento curricular no Brasil. In: Currículo: debates contemporâneos. 3 ed. São Paulo: Cortez, 2010. 
Revista de Educação, Ciência e Tecnologia
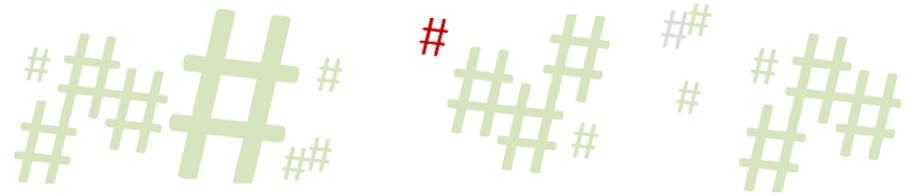

MATOS, J. M. C.; et al. Conteúdos de ensino da educação física escolar: saberes compartilhados nas narrativas docentes. Revista da Educação Física/UEM, Maringá. v.26. n.2. p. 181-199. 2015. Disponível em:

<http://www.periodicos.uem.br/ojs/index.php/RevEducFis/article/view/23200/15232>. Acesso em: 10 out. 2020.

MOURA, Dante Henrique. Educação básica e educação profissional e tecnológica: dualidade histórica e perspectivas de integração. Holos, ano 23, v. 2, p. 4-30, 2007. Disponível em: <http://www2.ifrn.edu.br/ojs/index.php/HOLOS/article/view/11/110>. Acesso em: 22 dez. 2019.

PALANCH, Wagner Barbosa de Lima; FREITAS, Adriano Vargas. Estado da arte como método de trabalho científico na área de educação matemática: possibilidades e limitações. Perspectivas da Educação Matemática, v. 8, número temático, p. 784-802, 2015. Disponível em: <https://periodicos.ufms.br/index.php/pedmat/article/view/867>. Acesso em: 15 dez. 2019.

PEREIRA, Flávio Medeiros; SILVA, Adriane Correa da. Sobre os conteúdos da educação física no ensino médio em diferentes redes educacionais do Rio Grande do Sul. Revista da Educação Física/UEM, Maringá, v. 15, n. 2, p. 67-77, 2004.

RAMOS, Marise. Concepção do ensino médio integrado. Seminário promovido pela Secretaria de Educação do Estado do Pará nos dias 08 e 09 de maio de 2008, p. 1-30, 2008. Disponível em: <https://tecnicadmiwj.files.wordpress.com/2008/09/texto-concepcaodo-ensino-medio-integrado-marise-ramos1.pdf >. Acesso em: 10 out. 2020.

SÁ. Katia Regina de. Currículo do ensino médio integrado do IFMG: a partitura, a polifonia e os solos da Educação Física. São Paulo: USP, 2019. TESE (Doutorado em Educação). Universidade de São Paulo, 2019.

SANTIN, Silvino. Educação física: uma abordagem filosófica da corporeidade. Ijuí: Unijuí, 1987.

SAVIANI, Demerval. A nova lei da educação: LDB, limite, trajetória e perspectivas. São Paulo: Autores Associados; 2003(a).

SAVIANI, Demerval. O choque teórico da politecnia. Trabalho, Educação e Saúde, v. 1, n. 1, p. 131-152, 2003(b). Disponível em <https://www.scielo.br/scielo.php?pid=S198177462003000100010\&script=sci_arttext\&tlng=pt>. Acesso em: 12 dez. 2019.

SILVA, Eduardo Marczwski da; FRAGA, Alex Branco. A história da Educação Física na educação profissional: entrada, saída e retorno à escola federal de Porto Alegre. Revista Brasileira de Educação Física e Esporte, v. 28, n. 2, p. 263-272, 2014. Disponível em <http://www.revistas.usp.br/rbefe/article/view/84068>. Acesso em 20 dez. 2019.

SILVA, Marcos Antonio da. Uma abordagem crítica do conteúdo esporte nas aulas de educação física no ensino médio integrado. Natal: UFRN, 2014. DISSERTAÇÃO (Mestrado em Educação): Universidade Federal do Rio Grande do Norte, 2014. 
Revista de Educação, Ciência e Tecnologia

SILVA, Tiago Amaral. A educação física no contexto dos cursos de educação profissional técnica de nível médio integrado do Instituto Federal de Educação, Ciência e Tecnologia de Mato Grosso do Sul. Cascavel: UNIOESTE, 2015. DISSERTAÇÃO (Mestrado em Educação): Universidade Estadual do Oeste do Paraná, 2015.

SOARES et al. Metodologia do ensino da educação física. São Paulo: Cortez, 1992.

SOARES, Fernanda Cristina Merisio Fernandes. O currículo prescrito da educação física num contexto de ensino médio integrado. Vitória: UFES, 2017. DISSERTAÇÃO (Mestrado em Educação Física): Universidade Federal do Espírito Santo, 2017.

SOUZA FILHO, Moisés de. Novas territorialidades pedagógicas para a educação física no ensino médio integrado: uma perspectiva pós-crítica. Natal: UFRN, 2014. TESE (Doutorado em Educação): Universidade Federal do Rio Grande do Norte, 2014.

SOUZA, Iracyara Maria Assunção de. A aplicação dos temas transversais nas aulas de educação física-ensino médio integrado. Natal: UFRN, 2013. DISSERTAÇÃO (Mestrado em Educação): Universidade Federal do Rio Grande do Norte, 2013.

VAGO, Tarcisio Mauro. Da ortopedia à eficiência dos corpos: a gymnastica e as exigências da "vida moderna" (Minas Gerais, 1906-1930). Movimento (ESEFID/UFRGS), v. 10, n. 3, p. 77-97, 2004.

VERENGUER, Rita de Cássia Garcia. Educação física escolar: considerações sobre a formação profissional do professor e o conteúdo do componente curricular no $2^{\circ}$ grau.

Revista Paulista de Educação Física, v. 9, n. 1 p. 69-74, 1995. Disponível em <http://www.revistas.usp.br/rpef/article/view/139420>. Acesso em: 22 dez. 2019.

ZABALA, Antoni. Enfoque globalizador e pensamento complexo. Porto Alegre: Artmed, 2002.

Recebido em abril de 2020.

Aprovado em novembro de 2020. 